\title{
Systems Dynamics Modelling in Industrial Development Evaluation
}

\author{
Sebastian Derwisch and Peter Löwe
}

\begin{abstract}
The complexity of development processes makes it difficult to observe and interpret the impacts of policies. The authors demonstrate the use and benefits of system dynamics modelling (SDM) in impact evaluation of private sector development programmes. A system dynamics model was hereby specifically used to compare the observed post-intervention situation with a hypothetical non-intervention scenario. They used the model to construct an optimal mix of interventions that supports sustainable private sector development. They found that developing a system dynamics model and 'gaming' with it is an appropriate means to link the behaviour of the industrial system we observe to its structural elements. This supports the understanding of the impact of complex interventions in industrial systems and can be further useful to convey lessons learned from the evaluations of complex systemic interventions.
\end{abstract}

\section{Introduction}

The inherent complexity, the cross-disciplinary nature and the long causal chains of development processes make it difficult to observe and interpret the impacts of policies. Ramalingam, Laric and Primrose (2014) state that challenges in development are, among others, often characterised by unclear definitions of problems, trade-offs between different development alternatives, and interdependencies of actors and institutions, which make a separation of single parts of the system difficult and replicability of solutions limited. This makes policy planning difficult as it reduces the ability of decision-makers to understand the future state of existing conditions and thus to design and evaluate effective strategies and policies (Pedercini 2009). Development policies can therefore lead to unexpected results (Saeed 2000). For understanding and anticipating the impact of a policy it is therefore essential to understand the structure and dynamics of the system at hand.

For this reason, systemic approaches in evaluation of development programmes are increasingly being discussed. Systemic approaches in evaluation focus on interrelations and the interaction between various stakeholders with different motivations, interests, perceptions and perspectives. ${ }^{1}$
One way to formalise systems thinking approaches is to use formal modelling, such as system dynamics. Ramalingam et al. (2014) applied SDM for a systemic evaluation of an aid programme in Nigeria. Another application of SDM for monitoring and evaluation is the model developed by Newman et al. (2003) for the malaria control programme in Bolivia. In the specific context of private sector development, Tarnburn (2008) states that causal models should provide the 'backbone' of any measurement of impacts but that such models are only valid for elements within an overall system such as a value chain. An example of an approach to causal models is the system dynamics model of the cocoa value chain in Indonesia (Borer 2006).

More recently, the Small Enterprise Education and Promotion Network (SEEP) of 'international practitioner organisations dedicated to combating poverty through promoting inclusive markets and financial systems' suggests that 'the focus of accountability has to shift from counting direct beneficiaries and assessing direct impacts at beneficiary level to a broader view of changes in the structures and dynamics of the market system with indirect effects on the target populations.' The spirit of using SDM in evaluation is reflected by Tarnburn (2008): 
The important point about this model is not so much its predictive capability, but more its value in enabling staff to think through the logic of their interventions. The design of this kind of model requires those involved to be more explicit about what they see as the key influences during implementation, and their relative importance in achieving the desired outcomes. It does also allow the effects of important delays to be included in the thinking... Once staff are more explicit about the causal model (or models) implicit in their work, then it is possible to validate this model, and measure the results, in more objective ways (Tarnburn 2008: 13).

This article reports on the effort of the evaluation group of the United Nations Industrial Development Organization (UNIDO) to use SDM in the context of programme evaluation. We demonstrate the use of SDM using the specific example of the UNIDO project 'Technical Assistance Project for the Upgrading of the Ethiopian Leather and Leather Products Industry'. At country level, the main purpose of the project has been to upgrade the leather and leather products industry.

UNIDO's SDM trials were conducted in parallel to the evaluation of a multiannual support programme for the Ethiopian leather sector (UNIDO 2012). The purpose of SDM development in the context of evaluation was to contribute to the impact evaluation of the programme. We therefore use SDM for establishing the counterfactual situation without UNIDO interventions on the one hand and for determining an optimal mix of UNIDO interventions to support the Ethiopian leather and leather products industry on the other hand. In this process, lessons learned in the course of UNIDO project evaluations were incorporated in the model.

We think that SDM is promising to enhance learning from evaluations of interventions in private sector development (PSD), which combine a range of simultaneous interventions. Our expectation is that SDM enables the identification and picturing of the impact channels that UNIDO attempts to simulate with these interventions. This should enhance learning from evaluation, the communication of lessons learned and eventually improve the design and coordination of UNIDO interventions. The main objectives of UNIDO's SDM effort are therefore:

to better understand the complex environments UNIDO operates in;

- to better understand the impact of private sector development programmes;

to better disseminate lessons learned from industrial upgrading (IU) and trade capacity building (TCB) evaluations.

\section{System dynamics methodology}

System dynamics is a computer-aided approach to policy analysis and design. It applies to dynamic problems (problems that involve change over time) arising in complex social, economic or ecological systems, i.e. in systems characterised by feedback loops, delays and non-linearities (Richardson 1991; Sterman 2000).

The system dynamics approach involves the development of a simulation model.

Experimentation with computer simulation models allows the virtual design and analysis of different scenarios and policies (Senge and Sterman 1994). Dynamic simulation models are sets of equations that describe the behaviour of dynamic systems. The models study the relationship between the underlying structure of a system and its behaviour. Given specified initial conditions and assumed behavioural parameters, the models trace the changes in key variables over time and allow the examination of the dynamic implications of the assumptions (Ruth and Hannon 1997). Mathematically, the basic structure of a formal dynamic simulation model consists of a system of coupled, non-linear, firstorder differential equations for modelling flows; or integral equations for modelling stocks.

Stocks, represented as integral equations, are critical in generating the dynamics of systems (Forrester 1961). They create delays where the output lags behind the input to a process. Such delays are an important element of dynamic systems and reflect the common sense experience that no action is performed instantaneously but takes time to perform. Stocks also provide the system with a memory as accumulations of resources can be modelled. Examples of stocks are capital (equipment), labour (jobs) and skills.

Flows are functions of the stocks and other parameters (Sterman 2000). Flows are represented 


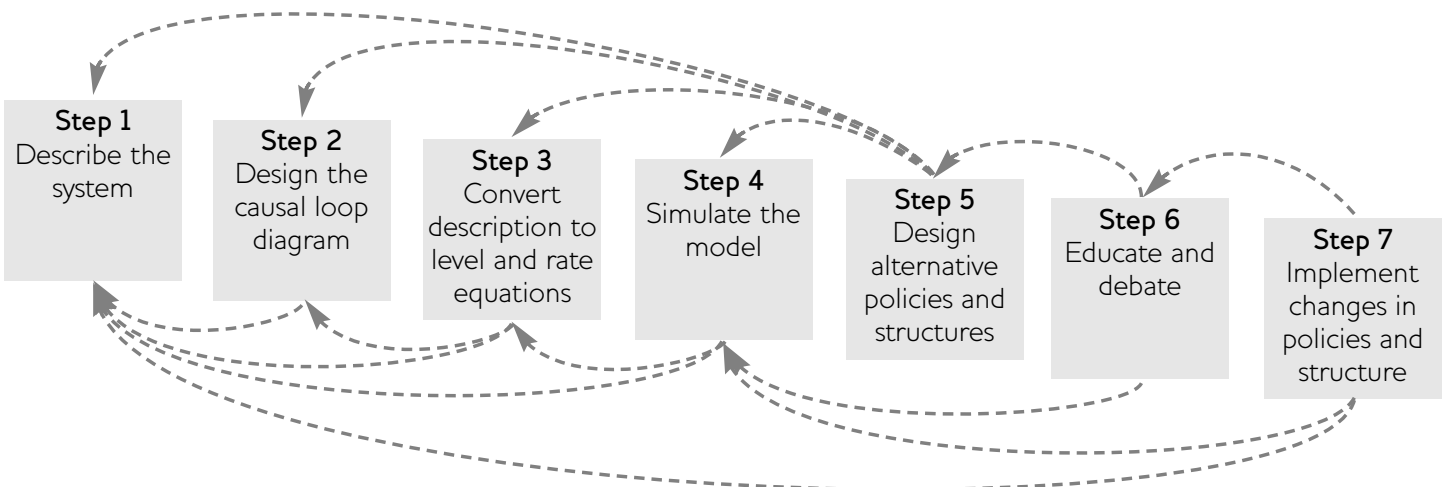

as differential equations and characterise the rate of change of stocks (Barlas 2002). Examples of flows are the number of employees hired per year or the amount of new equipment acquired per year. Parameters that influence flows represent exogenous inputs or constants such as the certification costs or the time that is needed to improve industrial processes. Simulation of such systems is accomplished by partitioning simulated time into discrete time intervals of length $d t$ and stepping the system through time one $d t$ at a time. By breaking the simulated time into discrete intervals $d t$ simulation makes the creation and use of models that include feedback and circular causality possible, thus expanding the range and complexity of problems that can be modelled (Richardson 1991). The simulation model that we develop is programmed using Vensim software, version 5.7.

\subsection{Developing a system dynamics model}

System dynamics model development involves a number of iterative steps ranging from knowledge elicitation and qualitative modelling to simulation of alternative scenarios.

The initial knowledge elicitation aims to identify the main variables, drivers and their relations in the context at hand, to agree on assumptions about their behaviour and to define the system boundaries, i.e. which variables are internal and which ones are external to the system. In Figure 1 this refers to steps 1-3. Knowledge elicitation can take place in a participative 'group model-building' workshop where stakeholders, often assisted by an external moderator, try to agree on a model that reflects their respective views and interests. Taking into account the so called Bonini's paradox ('The simple is false but the complex is unusable') the model should be a sound compromise that is neither too simple nor too broad or too complex. Different approaches exist, to introduce groups unfamiliar with SDM into the methodology in the course of a group model-building workshop (Richardson 2013).

The social setting of such a 'group modelbuilding' workshop is not very different from the 'goal-oriented project planning' workshops, which are well known participative project planning tools that have been in operation since the 1970s. However, using interrelated feedback loops as a meta-language instead of linear causal chains may help to avoid the above-mentioned pitfalls of over-simplification.

Important benefits of SDM arise at the simulation stage as it is precisely by simulating the behaviour of the system under different scenarios that its 'dynamic complexity' becomes tangible. This is a genuine added value of step 4 of SDM in Figure 1. Senge and Sterman (1994) state that the only practical way to test the assumptions behind a causal map is simulation, as the complexity produced by an elicitation workshop often exceeds what is comprehensible. Of course, simulation comes at a cost as it requires specialised software literacy and resources for transposing the causal loop diagram into a computer program.

To formalise a model, empirical data can be used - these can be time series data as well as correlation coefficients, etc. (Sterman 2000). However, Randers (1980) argues that one should not restrict a system dynamics model to the small amount of quantitative data as most 
knowledge is descriptive and contained in the experience of those familiar with the system. Qualitative data are seen as a main source of information in the modelling process (LunaReyes and Andersen 2003; Sterman 2000). A system dynamics model can therefore also be formalised by qualitative data, using expert opinions and mental models that are elicited in interviews or Delphi groups. Qualitative data serve as a basis for the model structure but can also be incorporated in the model formulation, for example via non-linear functions.

Once the model is formalised and can be used for simulation and understanding the implications of the causal structure, it can also be used for policy design and evaluation (Sterman 2000). Sterman stresses that policy design in system dynamics models not only encompasses the change of model parameters (like, for example, the time delay for hiring) but a redesign of the structure of the system at hand (eliminating time delays, changing information flows, etc.) to develop robust policies. This refers to steps 5-6 in Figure 1. Eventually these policies are implemented and monitored. Monitoring and evaluation can then lead to new results and assumptions, which can be used to redesign the simulation model or for building new scenarios, and so on.

\subsection{The problem of model validation}

The hybrid position of SDM between the conventional and simplistic 'causal chain' models on one side and the data-intensive macroeconomic models on the other, poses acceptability challenges with both practitioners and academics.

Project managers used to logframes tend to see SDM as overly complicated, while economists often have difficulties accepting that the system dynamics model structure and simulations may not be derived from statistics and 'hard facts' but from 'conversations with people involved' (Meadows 1980), hence their reluctance to embark on SDM and its perceived 'gut feeling' approach. This boils down to the problem of model validation. How 'objective' and 'empirically robust' is SDM? Exploring the question as to whether and how SDM can be empirically validated, Barlas and Carpenter (1990) hold the view that SDM is not 'truly scientific' in a positivist sense but that it is very much in line with contemporary relativistic theories of science. They regard model validity as being tied to the nature of the problem, the background of the user and the analyst and other environmental factors. Therefore, model validity cannot be proven but only judged subjectively.

It is important to understand that, from an SDM perspective, neither the structure of the model, nor its boundaries and nor even the variables are 'objective' facts but rather the results of a negotiation process among stakeholders.

Responding to the frequent scepticism that SDM cannot be 'validated' in a scientific way, Barlas and Carpenter (1990) underline that the 'validation' concept in itself has different meanings, depending on philosophical positions:

If one adopts a logical empiricist, foundationalist philosophy of model validation, then validation is seen as a strictly formal, algorithmic, reductionist, and 'confrontational' process. Since the model is assumed to be an objective and absolute representation of the real system, it can be either true or false. And given that the analyst uses the proper validation algorithms, once the model confronts the empirical facts, its truth (or falsehood) is automatically revealed. Validity becomes a matter of formal accuracy rather than practical use. If one takes a relativist, functional, holistic, philosophical approach, then validation becomes a semiformal, conversational process. A valid model is assumed to be only one of many possible ways of describing a real situation. [...] Models are not true or false but lie on a continuum of usefulness.

They stress that model validation is a process of building confidence in the model, which is achieved by social conversation, mainly because establishing model usefulness is a matter of conversation. Moreover, there are numerous ways to validate qualitative models such as structure assessment tests, extreme condition tests and sensitivity analysis (Sterman 2000).

\section{The test case}

Similar to most development support organisations, UNIDO uses standard causal chain modelling and logframes to depict the intervention logic of its programmes. However, recent UNIDO evaluations have indicated that these standard tools might fail to tackle the complexity of systemic interventions at national level. 
This is in line with other critical voices in the evaluation community. Richard Hummelbrunner (2010) has characterised the typical weaknesses of logframes and traditional causal modelling as follows:

- mechanistic rationale, assuming a 'linear' progression of effects which takes place quasiautomatically, i.e. irrespective of the actors involved or contextual conditions;

- long impact chains, where causes and effects are rather distant from each other, either in time or in their functional relations;

- external factors are considered almost irrelevant, leading to a tendency for 'tunnel vision'.

The current UNIDO toolbox falls short of alternatives. It is against this background that UNIDO has been exploring the potential of SDM as a tool for impact evaluation. Impact evaluation is structured to answer the question: how would outcomes such as participants' wellbeing have changed if the intervention had not been undertaken? This involves counterfactual analysis, that is, 'a comparison between what actually happened and what would have happened in the absence of the intervention.' (White 2006). SDM is expected to allow for a comparison between the 'treatment case' (the actual UNIDO intervention mix), the counterfactual case (without UNIDO interventions), and other possible intervention scenarios. Scenarios with no interventions or with hypothetic intervention mixes can be reconstructed, taken forward to a point of time in the future and compared with the actual intervention mix. The differences in impact/output variables between the two situations are then interpreted as 'the impact'.

As a test case for SDM in evaluation we used the UNIDO Technical Assistance Project for the upgrading of the Ethiopian leather and leather products industry. The development of SDM has been conducted as a side activity of the evaluation of this programme. UNIDO supported this sector by interventions in the areas of TCB and IU, which are meant to strengthen national quality systems (NQSs). Well-functioning NQSs (sometimes also labelled as 'quality infrastructure') are a key requirement for 'export capacity building' of developing countries. An NQS is composed of, inter alia, calibration and testing laboratories, inspection bodies and product certification schemes. Inspection bodies, for example, oversee local production, exports and imports. In this capacity, they are key enablers that provide linkages between testing and metrology laboratories (conformity assessment bodies) and the productive sector. NQSs help companies comply with international product quality standards and reap the potential benefits of globalisation (UNIDO 2006a, 2006b, 2006c).

Selecting this particular evaluation as a test case has been motivated by the comprehensive approach adopted by the programme under evaluation. The UNIDO programme started in the late 1990s with strengthening Ethiopian tanneries, and developed into a truly 'systemic' operation, including a 'master plan' for the Ethiopian leather sector drafted by UNIDO in 2005. The outputs of this master plan comprised:

- capacity building to enhance management capacity, workers' skills;

- marketing assistance to create brands and logos as well as to study potential export markets;

- improving access to credit for Ethiopian leather companies;

- product development and upgrading to introduce new products with higher export potential;

- improving labour and environmental standards of production.

UNIDO's Ethiopian leather programme aimed for impacts on different levels. The overall goal has been to improve the competitiveness of the Ethiopian leather sector by increasing the quality and product range of Ethiopian leather products. This should result in an increase of both national and international demand. At the same time, UNIDO aimed to increase employment and reduce poverty by higher productivity and better wages in the leather sector. In addition to policy support and upgrading of the NQSs, this should be achieved by better training for managers and workers in the leather industry and the provision of innovative equipment. In addition, improved environmental management and technologies should result in greater environmental sustainability, in particular of Ethiopian tanneries.

To focus SD model development, we chose the footwear sector as a subsector of the Ethiopian 


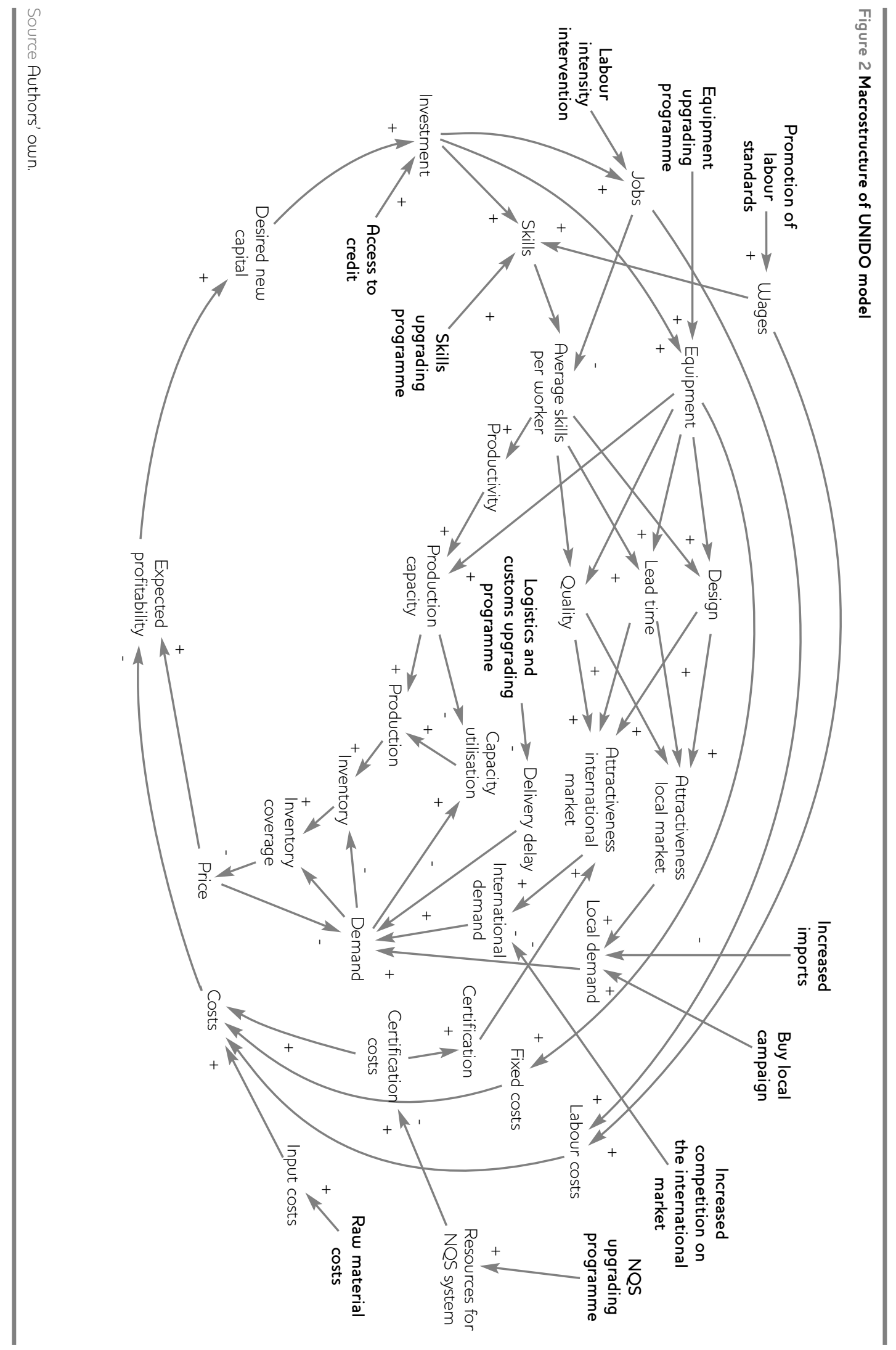


leather industry. The footwear sector plays a central role in the Ethiopian leather industry. Model boundaries are defined according to the definition of the problem. System dynamics models represent problems, not systems. SD model development therefore starts from a reference mode that defines the model boundaries (Saeed 1999). SDM development in our example was guided by the multiple goals of UNIDO in the leather sector regarding productivity, demand, employment and poverty and the corresponding target variables, which are described subsequently. The model includes processes relating to these goals and describing the interaction between these goals. As UNIDO interventions relate to these goals, those were included as policy parameters in the model.

\subsection{Building the UNIDO model}

To develop the UNIDO testing model we went through steps 1-5 of SDM development, which were described in Figure 1 (Borer 2006):

1 Bring together project staff and evaluators for a workshop to elicit knowledge and build consensus on the variables, drivers and relations in the system ('group model-building workshop');

2 Develop a causal diagram of the relationships between actors of the Ethiopian footwear sector and refine the model through dialogue with the group;

3 Formalise the model and test the computer model for plausible behaviour in different scenarios;

4 Simulate the model under different scenarios;

5 Design different policies and structures.

Starting with a group model-building workshop in November 2011, a process of reflection and dialogue was launched that eventually led to the model structure shown in Figure 2.

\subsubsection{Structure of the UNIDO simulation model}

The structure of the UNIDO model has been derived from the commodity market model by Sterman (2000) and was modified to fit the Ethiopian footwear production sector. The core of the footwear sector model consists of a major feedback loop displayed in Figure 2. In the following the equations of this feedback loop are described. As the model consists of over 200 equations, we will limit the model description to this feedback loop, to illustrate the logic behind a system dynamics simulation model. We start the description of the simulation model with investment $i$ into production capacity, which is determined by the initial investment $i_{\text {init }}$ and the expected profitability prof exp. The expected profitability is calculated out of the expected price $p_{e x p}$ and the expected $\cos t s c_{e x p}$ and gives a value analogous to percentage return per currency unit. The reader will notice how these equations are connected, each explaining how one parameter of another equation is obtained (these parameters are indicated in bold). The calculation of investment is displayed in Equation 1.

$$
\text { Equation } 1 \quad i=i_{\text {init }} *\left(\left(\boldsymbol{p}_{\text {exp }}-c_{\text {exp }}\right) / \boldsymbol{p}_{\text {expp }}\right)
$$

The expected price is a function of the initial price of shoes $p_{\text {init }}$, which is smoothed by a moving average. This is determined by the balance between supply and demand, expressed by the elasticity of $\cos t$ s on price $c_{\text {effect }}$, the inventory coverage that is calculated by the ratio between inventory $I$ and demand $d$ and the elasticity of inventory coverage on price $i c_{\text {effect }}$. The effect of costs on price $c_{\text {effect }}$ is upwards sloped. This reflects the assumption that higher costs incur a higher price. The effect of inventory coverage on price $i c_{\text {effect }}$ is downwards sloped. This reflects the assumption that a decreasing inventory coverage incurs an increasing price.

$$
\text { Equation } 2 \quad \boldsymbol{p}_{\text {exp }}=p_{\text {init }}\left(c^{*} c_{\text {effect }}\right) *\left((\boldsymbol{I} / d) * i c_{\text {effect }}\right)
$$

Inventory coverage is dependent on the inventory $I$, which represents supply. Inventory is determined by the production capacity $p c$, the productivity and the capacity utilisation $c u$ on the one hand and demand on the other hand, which is represented by sales $s$. Production capacity and productivity depend on the available production resources of skills and equipment. Investment into production resources (as seen in Equation 1) is determined by the expected profitability prof $f_{\text {exp }}$, which depends on the price $p$ and the $\operatorname{costs} c$. Higher prices lead to higher capacity utilisation $c u$ of the production capacity $p c$ and in the long run to additional capacity acquisition through investment into equipment and skills. Equation 3 shows how Inventory $I$ is calculated.

$$
\text { Equation } 3 \quad \boldsymbol{I}(t)=I(t 0)+[(p c * c u)-s] d t
$$

Demand depends on attractiveness of products, which is calculated in two steps. In the first step 


\begin{tabular}{lll}
\hline External variables & Intervention variables & Output variables \\
\hline Imports and import tariffs & Investment in equipment & Equipment \\
& Investment in skills & Skills \\
& Capital/labour intensity & Costs \\
& Access to credit & Productivity \\
& Strengthening of national quality infrastructure & Quality \\
& Logistics and customs infrastructure & International demand \\
& 'Buy local' campaign & Price \\
& Promotion of labour standards & Local demand \\
& Production \\
\end{tabular}

Source Authors' own.

design, quality and lead time are determined by production resources equipment $e$ and skills $s$. Design, lead time and quality are influenced differently by the capacity stocks of skills and equipment. The sensitivity of quality to a change in equipment $e e$ is 0.4 , the sensitivity of quality to a change in productivity epro is 0.4 and the sensitivity of quality to a change in skills $e s$ is 0.5 . Equation 4 shows how the input factors for quality are aggregated.

\section{Equation $4 \quad \boldsymbol{q}=q * e^{(e) *} * p_{r o}(e p r o) * S^{(e s)}$}

In the second step aggregate attractiveness is determined. Aggregate attractiveness is formed by different considerations that customers include in their purchasing decision. These factors are design $d$, lead time $l t$, quality $q$ and price $p_{r i}$ which are aggregated into the attractiveness $a$. The function by which attractiveness $a$ is formed represents our assumption of partial substitutability of input factors. Each of the input factors affects the attractiveness differently. In the equation this is represented by the sensitivity of attractiveness to a change of design $e d$, which is 0.3 , the sensitivity of attractiveness to a change of lead time elt, which is 0.2 , the sensitivity of attractiveness to a change of price epri, which is -0.5 and the sensitivity of attractiveness to a change of quality $e q$, which is 0.3. Equation 5 shows how attractiveness $a$ is formed.

\section{Equation $5 \quad a=d^{(e d) *} l t^{(e l l) *} \boldsymbol{p}^{(e p r i) *} \boldsymbol{q}^{(e q)}$}

The capacity stocks equipment, labour and skills are a function of investment. Equations 6-8 represent the resource stocks equipment $E$, skills $S$ and labour $L$. Equipment is determined by purchases $p_{\text {Equip }}$ and discards $d_{\text {Equip. }}$. Skills are determined by the sum of on-the-job training $p_{\text {Equip }}$ and the skill policy and the skill decay $d_{\text {Equip }}$.

Equation $6 \quad E(t)=E(t 0)+[$ purchase - discard $] d t$

\section{Equation 7}

$S(t)=S(t 0)+[j o b$ training + skill policy- skill decay $] d t$

\section{Equation $8 \quad L(t)=L(t 0)+[$ hiring - leaving $] d t$}

In the first phase of model development, represented in this article, statistical data of the variables included in the model were not considered. Instead, we initialised the model with the main parameters being 1 , so that changes in behaviour could be interpreted easily in terms of percentage change. The data we considered were qualitative in nature and parameters were calibrated so that the response of the system corresponded to the intuition of the experts at UNIDO. Several tests, such as structure behaviour tests and sensitivity analysis were run, in order to gain confidence in the model. 


\subsection{Scenarios and interventions}

Based on the model structure of the footwear sector and the policy interventions of the UNIDO programme, intervention variables and output variables were defined. Intervention variables represent UNIDO interventions. Output variables represent target variables of footwear sector development. These variables trace success of the UNIDO intervention and represent states of the system. In addition, variables of the external environment that are influential for the footwear sector were defined for scenario development. External, intervention and output variables are displayed in Table 1 .

External factors allow the building of different scenarios and impact the entire feedback structure. For example, imports and import tariffs represent an increase in imports of footwear on the national market as a consequence of the removal of import tariffs. The parameter can be varied between 0 (no competition - everything produced for the domestic market can be sold) and 1 (full competition, nothing produced for the domestic market can be sold). This parameter impacts on local demand and overall demand.

In addition, the system dynamics model offers the following eight variables that represent development interventions:

1 Investment in equipment: increases the stock of equipment while maintaining labour. The parameter can be varied between 0 (no additional investment in equipment) and 5 (investment in equipment increased by 500 per cent). This affects production capacity as well as attractiveness of products via lead time, quality and design.

2 Investment in skills: increases labour productivity. The parameter can be varied between 0 (no additional investment in skills) and 5 (investment in skills increased by 500 per cent). This affects production capacity as well as attractiveness of products via lead time, quality and design. However, the effect is different as skills have a much higher impact on quality than other production resources do.

3 Labour intensity: variation reflects different types of equipment, either increasing production capacity or saving labour.
Reducing labour intensity reduces jobs and maintains production. The parameter can be varied between -1 (full automatisation, no workers needed) and 1 (labour intensity increased by 100 per cent). This policy has an impact on employment (the number of jobs as well as the labour costs).

4 Access to credit: increases overall investment. The parameter can be varied between 0 (no additional investment) and 5 (investment increased by 500 per cent).

5 NQS upgrading programme: investment in NQS facilities. The parameter can be varied between 0 (no additional investment into NQS upgrading) and 5 (investment into NQS upgrading increased by 500 per cent).

Increasing this parameter increases costs for firms (certification, etc.). Hence, when only NQS upgrading is increased there will be an increase in costs by certification, which will in this specific scenario not be matched with an increase in demand but only increase costs. The increase in equipment and skills that is required to lift the attractiveness of the production to international standards is rather high.

\section{Logistics and customs upgrading programme:} investments to improve logistics and customs, which reduces fluctuations in the delivery delay and stabilises demand. The parameter can be varied between 0 (no additional investment into logistics) and 5 (investment into logistics increased by 500 per cent).

7 'Buy local' campaign: this intervention stimulates local demand and overall demand. The parameter can be varied between 0 (local demand remains stable) and 5 (local demand increased by 500 per cent).

8 Promotion of labour standards: better labour standards increase wages and higher wages increase both unit labour costs and skills per worker/productivity through process improvements or increased motivation. The parameter can be varied between 0 (local demand remains stable) and 5 (local demand increased by 500 per cent).

The response of the leather industry model is observed using 11 output variables that refer to 
the levels of impact that UNIDO targets. These output variables refer to the goals of the UNIDO intervention: increasing competitiveness and employment and reducing poverty. The output variables are listed in Table 1.

We first simulated the effect of an external shock and subsequently the impact of UNIDO interventions under the external shock scenario, using different combinations of intervention variables. The aim of simulating changes in external and intervention variables is to:

test how the system reacts to external shocks;

- test how the system reacts to UNIDO policies;

- test how the system reacts to different combinations of interventions and external shocks; and

- develop a scenario that combines different UNIDO interventions to maximise impact on sustainable footwear sector development under the shock scenario.

The model could be used to assess the impact of one particular policy mix; or even one particular single intervention, embedded in a context where other interventions (and possibly an external shock) are taking place.

The simulation was run from 2010 to 2035, taking into account the long delays in economic development. Vensim allows observing the response of the output parameters in year $n$ and reconfiguring the eight intervention parameters accordingly for year $n+1$. Interventions were adjusted stepwise over time, reflecting the choice of policymakers to vary interventions in timing and intensity. As such, the system allows experimenting (and impact-evaluating) within a virtually infinite number of policy mixes, allowing for the reconstruction of an infinite number of counterfactuals. Input levels can be simulated between 0 and 5 . Translated into realworld terms, these levels correspond to levels of investment. An additional constraint in simulating policies was introduced by limiting the 'budget' for interventions to represent tradeoffs in policy implementation. Therefore, in the game, the sum of all input levels in every given year should not exceed a certain amount. In the case presented a total 'budget' of about ten has been assumed. This reflects the need to make a choice among the interventions.

\section{Results of model simulation 4.1 Removal of trade barriers}

For simplicity we developed a model that was, in its initial state, in equilibrium. In the base case, therefore, output variables are constant and UNIDO interventions absent. We then introduced an 'external shock' scenario consisting of the removal of trade barriers and increased imports by 50 per cent, in the year 2011. The immediate result was a decrease in local demand leading to a series of delayed responses for production, costs, jobs, productivity, etc. The results can be seen in Figure 4, in the scenario 'Base case without UNIDO intervention'.

We observe that, apart from costs, the level of all output variables is decreasing. Increasing imports causes a decrease in local demand, causing decreasing expected profitability and investments. Equipment, jobs, quality and price respond with a time delay of about three years. The removal of trade barriers also bears the possibility of increased export demand. However, we observe a persisting lack of 'international demand'. The system dynamics model has been configured to reflect the assumption that local shoe production requires a number of interventions targeting quality, design and costs in order to become competitive. Without such interventions the national shoe industry will be exposed to increased competition without being able to grasp export opportunities.

\subsection{Behaviour of the system with systemic intervention}

The goal in the next step was to find the combination of UNIDO interventions, which would lead to the desired behaviour of the output variables in the context of the removal of trade barriers. This desired behaviour is marked by productivity growth, declines in costs and price, export to international markets, rising demand on local markets, employment creation combined with increasing wages and an increased production capacity. The mix of interventions leading to that desired behaviour is presented in Figure 3. This combination of interventions was found by 'trial and error', taking into account (or rather 'learning about') a number of hypotheses and evaluation findings built into the system. For example, 'NQS upgrading' and 'logistics and customs upgrading' are critical parameters with a very long response time. Therefore, the 'upgrading' of these parameters needs to be initiated from year one and with a relatively high input level of 2 . Other 

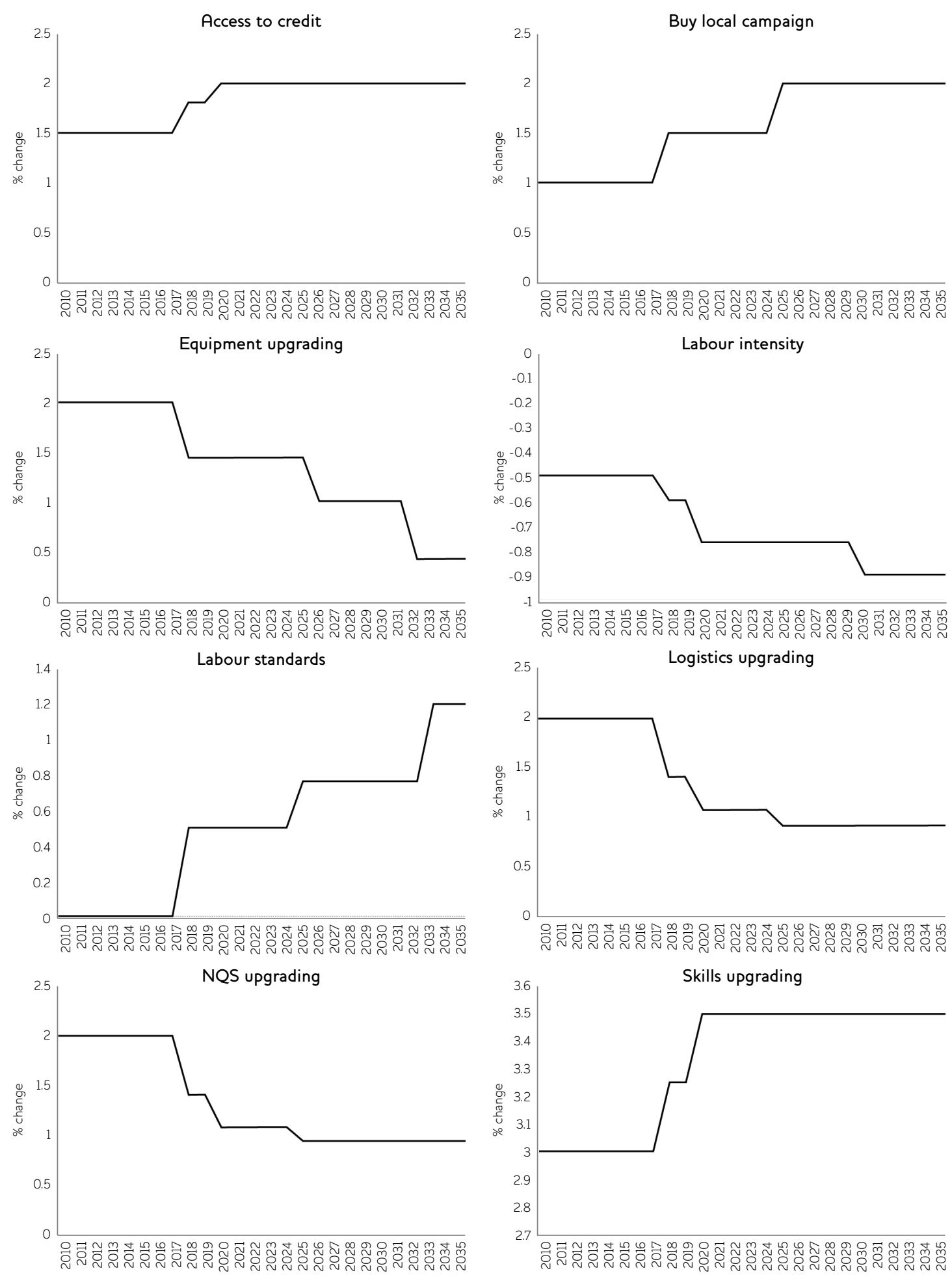
Figure 4 Simulated responses/interventions to removal of trade barriers without intervention and system behaviour in response to UNIDO interventions
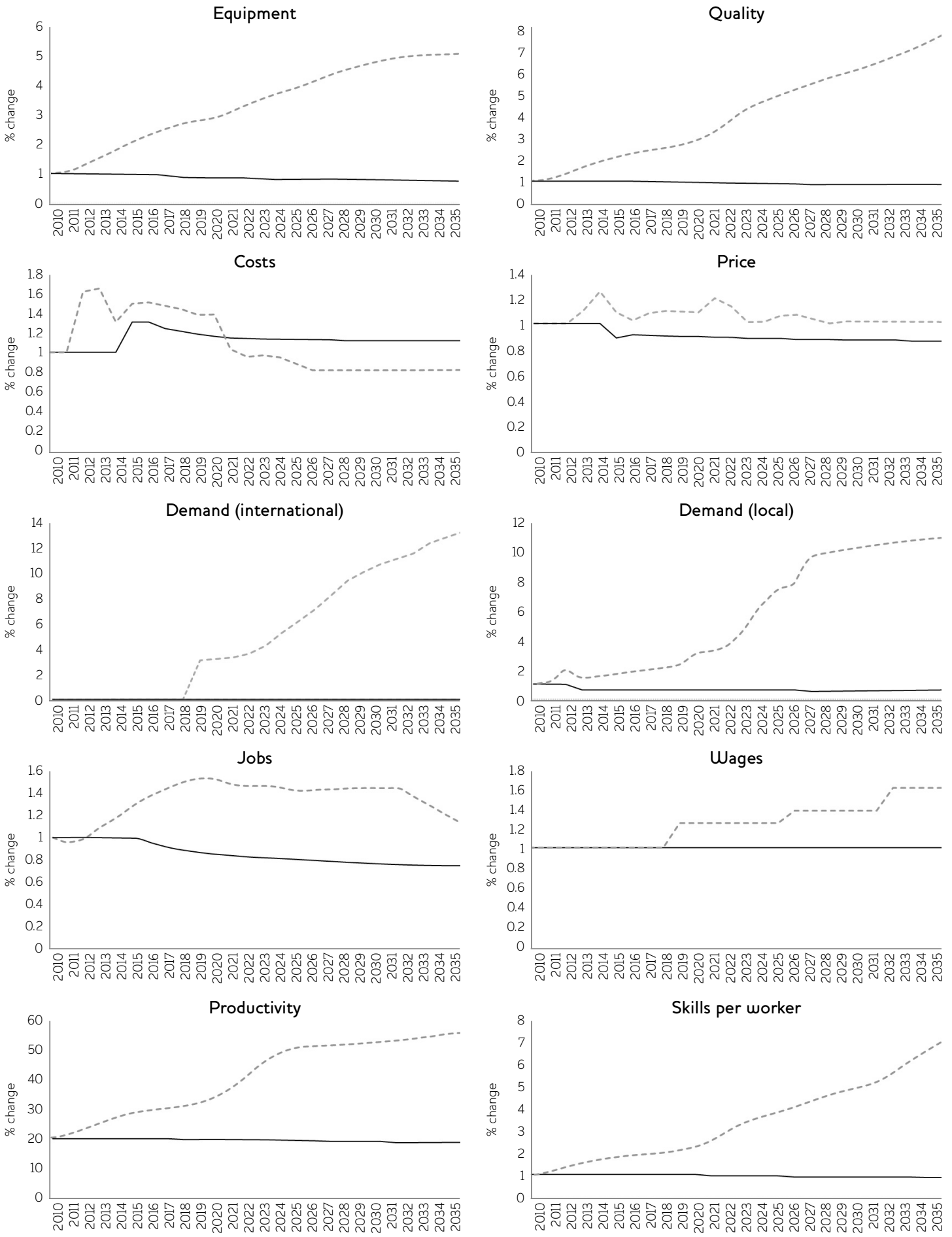

- UNIDO intervention scenario

Base case without UNIDO intervention

Source Authors' own. 
intervention parameters, such as 'investment in equipment', 'investment in skills' or 'labour standards' have shorter response times and can therefore be initiated later in the course of development and gradually. Interventions for equipment, skills, NQS upgrading, access to credits and logistics and customs started in the year 2010. The intensity of these interventions was increased stepwise over the simulation period.

The level of investment into equipment, logistics and customs upgrading as well as NQS upgrading were maintained in the beginning and reduced stepwise starting from the year 2018. Too much investment in equipment does have a negative impact on employment, which is why investments skills upgrading was preferred to increase productivity and quality. By these interventions, local demand was raised, jobs increased and quality, production and productivity were raised as well, as can be seen on the output variables in Figure 4 for the 'UNIDO intervention scenario'. In the year 2018 the attractiveness of Ethiopian products reaches a level which is high enough to trigger international demand. At the same time labour standards are raised, causing an increase in wages. Also NQS and logistic and customs upgrading are reduced as a response to successful export activity. This taken together causes temporarily stagnating levels of quality, production and productivity. But as local demand further increases (as a consequence of increased investments into marketing) and international demand is sustained, these output variables continue to grow over time.

\section{Conclusion}

The experiments with SDM for evaluation described in this article were conducted by the UNIDO Evaluation Group in the framework of a recent thematic evaluation of UNIDO's IU programmes. We have shown that SDM has the potential to become a promising evaluation tool for impact evaluation.

Developing a system dynamics model and 'gaming' with the computer model allows development of an improved understanding of the industrial sector at hand, to test different intervention and counterfactual scenarios and to better convey evaluation lessons.

The UNIDO experiments with SDM are in line with a wider movement in the evaluation community to explore new tools that are complementary to the standard logical framework approach (LFA) and the underlying linear causal models.

Causal loop models present a number of advantages over linear causal chains. In particular, SDM allows time-bound modelling and non-linear behaviour and demonstrates how development interventions are embedded in a larger context. SDM provides a better understanding as to why complex systemic interventions are necessary but also why such interventions do not 'cause' change in isolation but rather 'feed' into the mainstream dynamics of the existing system and its broader 'causal packages'.

The thematic evaluation confirmed that during the project design phase, causal loop models can facilitate reaching a common understanding on key variables, drivers, relationships and assumptions as well as priorities. Similar to problem and objective tree analysis, causal loop models could, once agreed among the stakeholders of a given project, accompany the project throughout its lifecycle from appraisal to evaluation. To ease the use of SDM for industrial development, generic causal loop models could be developed for certain types or 'families' of projects and used as a starting point for consensus building and planning processes.

Moving from qualitative to quantitative SDM presents additional advantages. Quantitative models allow testing conclusions that result from an evaluation by allowing the evaluator to 'game' with the model and to 'see' a variety of counterfactual situations. However, quantitative models come with additional costs in terms of programming, consensus building and eliciting knowledge about the assumed quantitative behaviour of variables.

In conclusion, SDM offers better insight into the complex interplay of systemic development interventions. SDM allows evaluation of the impact of such interventions while simulating external systemic shocks. Its potential in evaluation is considerable and justifies further experimentation and development work. 
1 GIZ conference on 'Systemic Approaches in Evaluation', 25-26 January 2011, Eschborn, Germany, www.evaluation-conference.de/en/ index.html.

\section{References}

Barlas, Y. (2002) 'System Dynamics: Systemic Feedback Modeling for Policy Analysis', Encyclopedia of Life Support Systems, Paris and Oxford: UNESCO Publishing

Barlas, Y. and Carpenter, S. (1990) 'Philosophical Roots of Model Validation: Two Paradigms', System Dynamics Review 6: 148-66

Borer, M. (2006) 'Application of System Dynamics in the International Development Cooperation. Analysis of Decision Taking Among Cocoa Farmers in Flores', Vol Business Process Manager, Zürich: University of Applied Sciences, North-western Switzerland

Forrester, J.W. (1961) Industrial Dynamics, Cambridge MA: MIT Press

Hummelbrunner, R. (2010) 'Beyond Logframe: Critique, Variations and Alternatives', Beyond Logframe; Using Systems Concepts in Evaluation, Tokyo: FASID

Luna-Reyes, L.F. and Andersen, D.L. (2003) 'Collecting and Analyzing Qualitative Data for System Dynamics: Methods and Models', System Dynamics Review 19: 271-96

Meadows, D. (1980) 'The Unavoidable A Priori', in J. Randers (ed.), Elements of the System Dynamics Method, Cambridge: Cambridge University Press

Newman, J.; Velasco, M.A.; Martin, L. and Fantini, A.M. (2003) 'A System Dynamics Approach to Monitoring and Evaluation at the Country Level: An Application to the Evaluation of Malaria-Control Programs in Bolivia', World Bank Conference of the Operations of Evaluations Department on Evaluation and Development, Washington DC: World Bank

Pedercini, M. (2009) 'Modelling Resource Based Growth for Development Policy Analysis', Social Sciences, Vol. Doctorial Thesis, Bergen: University of Bergen

Ramalingam, B.; Laric, M. and Primrose, J. (2014) From Best Practice to Best Fit: Understanding and Navigating Wicked Problems in International Development, Working Paper, London: ODI

Randers, J. (1980) 'Guidelines for Model Conceptualization', in J. Randers (ed.), Elements of the System Dynamics Method, Cambridge: Cambridge University Press
Richardson, G.P. (2013) 'Concept Models in Group Model Building', System Dynamics Review 29: 42-55

Richardson, G.P. (1991) 'System Dynamics: Simulation for Policy Analysis from a Feedback Perspective', Qualitative Simulation Modeling and Analysis Advances in Simulation 5: 144-69

Ruth, M. and Hannon, B. (1997) Modeling Dynamic Economic Systems, New York NY: Springer

Saeed, K. (2000) The Pervasive Duality in Economic Systems: Implications for Economic Development and Poverty Alleviation, Worcester MA: Worcester Polytechnic Institute

Saeed, K. (1999) Defining a Problem or Constructing a Reference Mode, Worcester MA: Worcester Polytechnic Institute, Social Science and Policy Studies Department

Senge, P.M. and Sterman, J.D. (1994) 'Systems Thinking and Organizational Learning: Acting Locally and Thinking Globally in the Organization of the Future', in J.D.W. Morecroft and J.D. Sterman (eds), Modeling for Learning Organizations, Portland OR: Productivity Press

Sterman, J.D. (2000) Business Dynamics. Systems Thinking and Modeling for a Complex World, Boston: Irwin McGraw-Hill

Tarnburn, J. (2008) 'The 2008 Reader on Private Sector Development: Measuring and Reporting Results', Eighth Annual Seminar on Developing Service Markets and Value Chains, Chiang Mai, Thailand

UNIDO (2012) Technical Assistance Project for the Upgrading of the Ethiopia Leather and Leather Products Industry, Vienna: UNIDO

UNIDO (2006a) Product Quality. A Guide for Small and Medium-sized Enterprises, Vienna: UNIDO

UNIDO (2006b) Role of Measurement and Calibration in the Manufacture of Products for the Global Market. A Guide for Small and MediumSized Enterprises, Vienna: UNIDO

UNIDO (2006c) Role of Standards. A Guide for Small and Medium-sized Enterprises, Vienna: UNIDO

White, H. (2006) Impact Evaluation: The Experience of the Independent Evaluation Group of the World Bank, Washington DC: World Bank 